\title{
La vuelta del FMI a la Argentina en 2018 desde una perspectiva neogramsciana
}

Germán Ezequiel Ricci*

\section{Resumen}

Este artículo analiza el nuevo acuerdo entre el Fondo Monetario Internacional (FMI) y Argentina firmado en el año 2018. Considerando la experiencia previa con el Fondo, contesto qué hay de nuevo en este periodo de endeudamiento. Desde la perspectiva neogramsciana, argumento que el FMI ha aplicado la estrategia de transformismo al incorporar un novedoso "pilar social" destinado a los pobres y las mujeres. Basado en el uso de fuentes primarias y secundarias, sostengo que la consideración de la pobreza fue un intento del Fondo por auto legitimar su regreso y desarticular el posible avance contrahegemónico, ya que buscó incorporar a aquellos que obstaculizaron la implementación de la agenda neoliberal hacia fines de los 90. A su vez, demuestro que la perspectiva de género carece de contenido y condicionalidades, por lo que opera como una estrategia discursiva para legitimar el Acuerdo al tomar un tema relevante en la agenda local. En cualquier caso, el pilar social no ha sido suficiente para consolidar una nueva hegemonía neoliberal.

Palabras clave: Argentina - FMI - neoliberalismo - transformismo neogramsciano

\section{The IMF's return to Argentina in 2018 from a neo-Gramscian perspective}

\begin{abstract}
This study analyzes the new agreement between the IMF and Argentina signed in 2018. Considering the previous experience with the Fund, I answer what is new in this period of indebtedness. From a neoGramscian perspective, I argue that the IMF has applied the strategy of transformism by incorporating a novel "social pillar" aimed at the poor and women. Based on the use of primary and secondary sources, I argue that the consideration of poverty was an attempt by the Fund to legitimize its return and dismantle the possible counter-hegemonic advance since it sought to incorporate those who hindered the implementation of the neoliberal agenda towards the end of the 90s. In turn, I show that the gender perspective lacks content and conditionalities, so it operates as a discursive strategy to legitimize the agreement by taking a relevant issue on the local agenda. In any case, the social pillar has not been enough to consolidate a new neoliberal hegemony.
\end{abstract}

Key Words: Argentina - IMF - neoliberalism - transformism neo-Gramscian

TRABAJO RECIBIDO: 23/07/2020 TRABAJO ACEPTADO: 17/10/2020

\footnotetext{
Master en Políticas Públicas, The University of Sydney (Australia). Correo electrónico: ger_ricci18@hotmail.com
} 


\section{Introducción}

Este artículo se centra en el Acuerdo Stand-by firmado entre Argentina y el FMI en el 2018 por USD \$ 57.000 millones, el préstamo más grande otorgado por el Fondo en su historia. Para analizar esta nueva intervención del Fondo se revisan los periodos previos de endeudamiento entre la Argentina y el FMI y se tiene en cuenta el contexto económico y político local en el que se inscribe el nuevo acuerdo. El estudio se extiende hasta las elecciones presidenciales de octubre del año 2019.

La solicitud de un nuevo préstamo fue controversial ya que Argentina había previamente trabajado con el FMI desde 1958 y los resultados de todos los programas de ajuste propuestos por el Fondo incrementaron el desempleo, la pobreza y la inequidad (Brenta, 2011b). De hecho, el último acuerdo finalizó tras la suspensión del programa en el 2001, que consecuentemente derivó en una crisis económica, política y social sin precedentes (Nemiña, 2011).

Pocos meses después del colapso económico, la Oficina de Evaluación Independiente (IOE) del FMI analizó las causas de la experiencia fallida con la Argentina y el rol del Fondo. Por un lado, la IOE reconoció que su reputación se había visto dañada por los resultados económicos y a modo de "autocrítica", la IOE enumeró una serie de lecciones aprendidas que incluían, entre otras, la necesidad de supervisar firmemente las metas acordadas (IOE, 2004). Sin embargo, evidenciaré que esto vuelve a repetirse durante el proceso de implementación del nuevo acuerdo. En este sentido, esta investigación busca contestar ¿Qué hay de nuevo en el FMI? ¿Qué es lo que verdaderamente aprendió tras la fallida experiencia del 2001 ?

Como se demostrará en las próximas secciones, uno de los elementos distintivos del nuevo acuerdo es la consideración sobre "los vulnerables", algo que había sido ignorado en las experiencias previas, incluso en la reciente experiencia griega. Si bien el Acuerdo es un plan tradicional de ajuste basado en los pilares fiscal, monetario y bancario, se introdujo un novedoso cuarto pilar (desde ahora en adelante "pilar social") que aborda a los sectores vulnerables, integrados por los pobres y las mujeres. Frente a esto, me pregunto ¿Cuál es el alcance material e ideológico del pilar social en el Acuerdo?

Desde una perspectiva neogramsciana, este artículo evidencia que la inclusión del pilar social no fue suficiente para reducir el incremento de la desigualdad ni la pobreza. En todo caso, sirvió para legitimar el regreso del Fondo y su programa de ajuste al incorporar una lógica de contención pos exclusión de modo tal de garantizar el consenso alrededor de la agenda pro mercado. Argumento que el FMI y el gobierno local han aplicado una estrategia de transformismo al incluir en el Acuerdo potenciales ideas y grupos subalternos con el objetivo de desmotivar la resistencia social, tal como emergió en el 2001 en Argentina y más recientemente en Grecia en el 2009. A través del pilar social, el FMI buscó establecer una alianza con los sectores perjudicados durante las experiencias previas $\mathrm{y}$, de esa forma, desarticular posibles reacciones contrahegemónicas. Se demostrará que el modo en el que los vulnerables son alcanzados en el nuevo acuerdo revela que el FMI aprendió que la pobreza no es algo a combatir o ignorar, sino algo que contener.

De todas formas, el contenido y el alcance económico del pilar social fue limitado. Su poder de compra es mínimo y solo implicó la extensión de las políticas locales asistenciales vigentes del gobierno argentino. Con respecto a la perspectiva de género que propone, demostraré que este tema ha sido incluido solo discursivamente como una estrategia para legitimar el Acuerdo ya que no se han definido recursos, programas u objetivos específicos para promover la igualdad de género y que muy por el contrario a lo enunciado, este tipo de programa resulta perjudicial para las mujeres. La reivindicación discursiva del FMI sobre ciertos tópicos de interés local es una estrategia repetida por el Organismo en varias oportunidades a nivel global durante las últimas décadas.

En la próxima sección de este artículo discutiré la literatura política económica internacional en relación al FMI con el objetivo de definir cuál es perspectiva teórica más adecuada para analizar el nuevo acuerdo. Posteriormente, se analizan las intervenciones previas del FMI en 
Argentina para conocer bajo qué antecedentes se establece el nuevo acuerdo firmado en el 2018. La tercera sección de este trabajo analiza la crisis de legitimidad y discute la reforma del Fondo, al contemplar el reciente caso griego. En la cuarta sección, se estudia el camino hacia el nuevo acuerdo con Argentina para comprender en qué contexto económico y político surge este nuevo préstamo. Posteriormente, analizo el contenido del nuevo acuerdo y su proceso de implementación, hasta los resultados, utilizando fuentes primarias (los documentos oficiales firmados por Argentina y el FMI y las primeras cuatro revisiones del Acuerdo e información estadística relacionada con inequidad, pobreza y desempleo provista por el INDEC y la Encuesta Permanente de Hogares).

Por último, concluyo que el pilar social, bajo la técnica del transformismo, estuvo destinado a legitimar la vuelta del Fondo y garantizar la implementación del ajuste al contener a los mismos que excluye. Sin embargo, algunos de los sectores destinados a ser contenidos han reaccionado como consecuencia de los recientes resultados socioeconómicos, lo que pone en crisis la consolidación del proyecto hegemónico neoliberal iniciado en 2015.

\section{Teorizando la influencia y poder del FMI}

El análisis del comportamiento del FMI puede realizarse desde distintas perspectivas teóricas. Una de las principales corrientes de pensamiento está compuesta por los "Institucionalistas Neoliberales" que argumentan que, en el contexto de la globalización, las organizaciones internacionales están basadas en acuerdos de cooperación mutua (Keohane, 1984). Así, las instituciones globales vendrían a resolver problemas de coordinación y ayudar a los Estados en temas internacionales y domésticos. Esta perspectiva argumenta que las instituciones globales tienen un rol modesto en comparación con los Estados (Checkel, 1998, p. 329).

Sin embargo, esta perspectiva es problemática en dos sentidos. Por un lado, no considera las preferencias político-económicas de los organismos internacionales. En América Latina, los programas del Fondo promovieron políticas económicas propias del neoliberalismo, asociadas al Consenso de Washington que implicaron el retiro del Estado, un plan de privatizaciones masivas, la desregulación de los mercados, y la liberalización del sistema financiero y comercial (Girón, 2010). Por otra parte, los Institucionalistas Neoliberales no reconocen los mecanismos de poder con los que cuentan los organismos internacionales para privilegiar ciertos programas económicos por sobre otros. El Fondo puede suspender un acuerdo o enviar señales negativas a los mercados internacionales de capital, lo que inevitablemente puede funcionar como un mecanismo para presionar a los Estados para que adopten determinadas políticas económicas (Doyle, 2012, p. 576). Esto se ve agravado por la situación de crisis que atraviesan los países que deciden recurrir al FMI, que menoscaba su margen de negociación (Ellison, 2017, p. 19).

Existen otras perspectivas que efectivamente consideran las asimetrías de poder y el carácter ideológico de los organismos internacionales. Esta corriente está representada por los neorrealistas, que argumentan que las organizaciones internacionales están embebidas en jerarquías globales, y que son espejo de la distribución asimétrica de poder político y económico entre Estados (Riggirozi, 2005, p. 63). Este sería el caso del FMI, cuya composición interna es suficiente para entender la capacidad de influencia que cada país miembro tiene: la distribución de poder responde al tamaño de las cuotas con que contribuye cada Estado miembro. Actualmente, Estados Unidos es el mayor contribuyente y su sola abstención es suficiente para cancelar cualquier iniciativa que involucre el consenso de una mayoría calificada (Blanchard et al., 2010).

La visión unilateral de poder de la perspectiva neorrealista presenta ciertas limitaciones ya que omite la capacidad de resistencia (o complicidad) de los agentes locales y desconoce completamente la autonomía de las organizaciones internacionales. Para el caso del FMI esto es problemático en dos sentidos: por un lado, a diferencia de otras organizaciones internacionales que dependen exclusivamente del capital aportado por los Estados, el Fondo, como entidad financiera, tiene la capacidad de generar sus propios ingresos por lo que alcanza un grado de autonomía mayor que otras organizaciones (Nelson, 2017). Por otro lado, si bien la asimétrica distribución estructural del FMI tendería a promover la defensa de ciertos intereses por sobre otros (los de 
aquellos Estados que tienen más poder de decisión), también se debe considerar que, en cada intervención, el FMI pone su propia legitimidad en juego. De hecho, varios autores han señalado que, a principios del siglo XXI, el FMI experimentó una crisis de legitimidad en la región latinoamericana y éste reduzco drásticamente su participación en la economía regional (Jiménez y Lorenzo, 2010; Martone, 2004). En este sentido, no se debe desconocer la historia previa que tienen los Estados con el Fondo. Al entender que el neoliberalismo es una doctrina que se redefine y actualiza las ideas básicas del liberalismo a los tiempos actuales, un cuerpo teórico de premisas orientadas a la aplicación práctica (Harvey, 2007), es de esperar que la experiencia previa que cada Estado mantuvo con el Fondo influya en las nuevas intervenciones.

La perspectiva neogramsciana aparece como una alternativa que subsana los aspectos problemáticos de la perspectiva neorrealista. En relación a la visión unilateral del poder, los neogramscianos se interesan en cómo el poder opera en el sistema internacional, no solo a través de coerción, sino también de consenso (Cox, 2016). Esto permite reconocer a los agentes locales e implica que distintos actores pueden desarrollar alianzas para construir un nuevo bloque ideológico dominante. La hegemonía sería el resultado de la combinación eficaz entre dominación intelectual y liderazgo moral.

Por otro lado, desde esta perspectiva es posible interpretar las transformaciones de los organismos internacionales a partir de las experiencias previas. La crisis de legitimidad que experimentó el Fondo en Argentina en particular y en América Latina en general puede interpretarse como un daño a su liderazgo intelectual y moral del FMI y su agenda neoliberal tradicional. En este sentido, el análisis del nuevo acuerdo debe comprender la construcción de un nuevo consenso y esto puede implicar la inclusión de nuevos aspectos ideológicos en su agenda. Esta estrategia es conocida como transformismo que es definida como un método gradual pero continuo de absorción de grupos aliados e incluso grupos antagónicos para lograr una nueva hegemonía (Mueller, 2011, p. 397).

De todas formas, el transformismo no especifica hasta qué punto los nuevos incluidos en el nuevo consenso se beneficiarán. La inclusión puede ser meramente discursiva sin consecuencias prácticas de magnitud, como fue la "preocupación" creciente del Fondo por cuestiones de interés local, como la corrupción, el cambio climático o la inequidad (Taylor, 2004; Forster et al., 2019). O también puede implicar la inclusión de temas que son propios de los detractores del Fondo para canalizar el descontento frente al neoliberalismo (Mueller, 2011). Estos fueron los casos en los que el FMI incluyó la "Red de Seguridad Social" en 1993 o las "Estrategias de Reducción de la Pobreza" en 1999, con el objetivo de contrarrestar las críticas hacia las reformas económicas propuestas y otorgar viabilidad política a su agenda neoliberal (Nemiña \& Echandi, 2020). Estos cambios del Fondo -o "aggiornamentos periódicos" en términos de Musacchio (2020)- han servido como estrategia para legitimar su intervención con los programas de ajuste.

Para que estos temas no sean solo una mera declaración de intensión, deberían estar dotados de recursos y acompañados de condicionalidades durante los programas; es decir, de una serie de reglas que aseguren el cumplimiento de los objetivos propuestos. Por lo tanto, los cambios en el discurso del FMI advierten a mi investigación sobre las estrategias de legitimación del Fondo y la necesidad de evaluar el alcance práctico de aquello que sea introducido discursivamente como novedoso.

\section{Antecedentes de la relación entre Argentina y el FMI}

La relación entre Argentina y el FMI ha sido cambiante e intensa. Fue el último país latinoamericano en adherirse al Acuerdo de Bretton Woods y establecer relaciones formales con el Fondo. En 1944, Argentina había sido excluida de formar parte del mencionado Acuerdo, ya que se cuestionaba la falta de alineamiento político con Estados Unidos y su neutralidad en la Segunda Guerra Mundial (Kedar, 2012). Sin embargo, finalmente Argentina se adhirió a los Acuerdos de Bretton Woods durante el gobierno de la Revolución Libertadora en 1956. Para ello, antes tuvo 
que reformar su economía y modificar sus relaciones económicas internacionales (Giavedoni, 2018).

A tan solo dos años de ingresar, Argentina firmó su primer programa para estabilizar su economía en 1958 y desde entonces trabajó bajo la supervisión del Fondo durante 38 años casi ininterrumpidos. Desde ese año hasta el 2004, Argentina firmó veintiún acuerdos. Si bien el FMI es una organización prestamista, en Argentina históricamente funcionó como un catalizador de fondos privados ya que sus préstamos solo representaron entre el $4 \%$ y el 5\% de la deuda pública externa. El sello de la organización ha facilitado el acceso a los mercados globales (Brenta, 2011a).

Desde los 70, el FMI ha promovido en Argentina programas neoliberales bajo la premisa de "ajustes estructurales" que cuestionaron el tamaño y las funciones del Estado. Varios investigadores han sido críticos de los efectos del Fondo ya que estos programas no solo no han podido corregir la balanza de pagos a corto y mediano plazo, sino que además han afectado negativamente el crecimiento económico, el empleo y la desigualdad a largo plazo (Brenta, 2011b).

\subsection{El último periodo de endeudamiento entre Argentina y el FMI}

Previo al Acuerdo sancionado en junio del 2018, Argentina experimentó un ciclo de endeudamiento con el Fondo que se extendió desde finales de 1989 hasta el año 2006. Si bien, como se señaló más arriba, el Fondo trabajó con Argentina casi ininterrumpidamente, las elecciones nacionales de 1989 implicaron el cambio de signo político gobernante, dando origen al menemismo, lo que produjo un nuevo tipo de vinculación hasta finales de los 90. La coincidencia en un programa económico neoliberal entre el staff del Fondo y los funcionarios locales durante los 90 le permitió al gobierno argentino una supervisión laxa y flexible durante el Acuerdo que se diferenció del periodo previo de endeudamiento donde el Fondo se había mostrado inflexible en algunas oportunidades durante el alfonsinismo (Nelson, 2017, pp. 118-165). A partir del menemismo, el FMI y Argentina firmaron cuatro acuerdos Stand-by en 1989, 1991, 1996 y 2000, dos facilidades extendidas en 1992 y 1998, y una complementación de reservas en el 2001 (Brenta, 2011a). Al igual que para el resto de América Latina, durante estos años los acuerdos promovieron ideas asociadas al Consenso de Washington que implicaron la liberalización de la economía, en detrimento del rol del Estado. Después de una década de reformas, Argentina logró tener uno de los sistemas públicos más chicos del mundo (Manzo y Salva, 2012).

En relación a la política internacional, Argentina se había alineado con Estados Unidos. La afinidad político-económica con el Estado miembro del Fondo más poderoso también le permitió a la Argentina aumentar su margen de negociación durante el Acuerdo. Si bien Argentina no cumplió con varias de las condicionalidades planteadas en el programa, el mismo siguió vigente durante la década al recibir waivers (Nelson, 2017).

La política económica de los 90 estuvo principalmente basada en el plan de "convertibilidad" que consistía en fijar el tipo de cambio entre el peso argentino y el dólar americano. Esta estrategia fue eficaz en el corto plazo ya que permitió corregir el proceso inflacionario desatado a fines de la década del 80, pero con el correr de los años, el peso argentino quedó sobrevaluado y esto promovió las importaciones a expensas de las exportaciones, lo que provocó un creciente déficit fiscal y comercial. En este escenario, la contracción de deuda pasó a ser la principal fuente de divisas para financiar los desbalances económicos. De este modo, el programa desencadenó en la promoción de la especulación financiera, y gradualmente consolidó un periodo de desindustrialización que a su vez produjo un incremento en la desigualdad económica, el desempleo y la pobreza (Nemiña, 2011).

Además de la progresiva exclusión social, el programa también enfrentó dificultades financieras después de los cambios en el mercado internacional. La crisis del Tequila en 1994, seguida de la crisis del Este asiático y la crisis rusa en 1997, y la crisis brasileña en 1998, obstaculizaron el acceso al crédito internacional. En este contexto, el FMI presionó al gobierno argentino para que encarara reformas con el objetivo de minimizar el gasto del Estado. El Fondo 
propuso reducir los gastos sociales al incrementar la edad jubilatoria a las mujeres, reducir el salario de los jubilados y una reforma laboral. Si bien el gobierno intentó seguir las instrucciones, se vio doblemente obstaculizado. Por un lado, no pudo canalizar el descontento social que se manifestaba a través de las movilizaciones sociales en las calles. Durante la década, emergieron nuevos actores como los movimientos de los desempleados, la Central de Trabajadores Argentinos (CTA) y los piqueteros que se opusieron a las medidas recetadas por el Fondo (Dinerstein, 2004). Por otro lado, la Justicia declaró inconstitucional algunos de los decretos promovidos por el FMI para la recaudación del gobierno, como la mencionada reforma jubilatoria (Natanson, 2019). Además, en los casos en los que el gobierno fue capaz de reducir el gasto social, estos logros fueron parcialmente socavados por la recesión económica que afectó la recaudación impositiva e incrementó el déficit fiscal (Manzo y Salva, 2012).

Hacia finales de la década de los 90, la profundización de la crisis económica empezó a mermar la relación entre el FMI y Argentina. Primero, el Fondo no tenía el mismo grado de confianza con las políticas económicas de la alianza radical liderada por el presidente de la Rúa (1999-2001) que con el menemismo (1989-1999) (Nelson, 2017). A su vez, la derrota del oficialismo en las elecciones legislativas del 2001, redujo el poder del gobierno a nivel local, lo que dificultaba aún más la implementación de las recetas del Fondo. Segundo, la asunción de Bush en Estados Unidos, también afectó la relación Argentina-FMI ya que implicó un cambio en la posición internacional del Fondo, que adoptó una perspectiva conservadora con respecto al crédito destinado a países en desarrollo (Nemiña, 2011). Desde entonces, el Fondo adoptó una postura rigurosa para el cumplimiento de los objetivos acordados con Argentina, y presionó al país sudamericano para que profundizara el ajuste fiscal.

Durante la profundización de la crisis económica, el gobierno argentino tomó algunas medidas económicas para aliviar la creciente conflictividad social a nivel nacional e incrementar la recolección fiscal sin consultar primero al Fondo. El por entonces Ministro de Economía Cavallo, impulsó un impuesto a las transacciones financieras, compensaciones comerciales para exportadores e importadores (que era una especie de devaluación encubierta), controles monetarios para los bancos y para las transacciones de cambio, y restricciones para transferencias económicas para el exterior y viajes. Estas medidas fueron rechazadas por el FMI. Para evitar la fuga de capitales, posteriormente Cavallo implementó el "corralito", que era una política monetaria que restringía el retiro de depósitos para evitar desfinanciar al sistema bancario. Frente a esta medida, el Fondo retiró totalmente el apoyo a la Argentina (Nemiña, 2011). En esta ocasión, el FMI fue estricto en el monitoreo de los objetivos fiscales y suspendió la quinta revisión del Acuerdo, cancelando el desembolso programado de USD $\$ 1.3$ billones.

La suspensión del crédito en diciembre del 2001 desencadenó en la renuncia del Ministro de Economía, seguido del presidente de la Nación y la posterior declaración de default para el pago de la deuda externa. En los meses subsiguientes, la moneda nacional fue devaluada un 300\%, y los indicadores sociales empeoraron; tanto el desempleo como la pobreza alcanzaron su pico histórico ( $19.7 \%$ y $49.7 \%$, respectivamente). Además, las manifestaciones sociales como consecuencia de la crisis desencadenaron en la muerte de 39 personas.

En el contexto de la crisis económica, el sistema político fue cuestionado en su totalidad; la deuda argentina, que se había tornado impagable, junto con el descontento social, redujeron el margen de maniobra del Poder Ejecutivo y esto causó una crisis institucional sin precedentes en la que Argentina llegó a tener 5 presidentes en 12 días. Las insurrecciones sociales evidenciaron un proceso de crisis de representación política conocida como "Los Huérfanos de la Política" (Torre, 2005). La huella más visible de este descrédito político pudo verse en las elecciones legislativas de octubre del 2001, meses antes del estallido social. En esa elección, los votos positivos alcanzaron tan solo el $76 \%$, muy por debajo de los porcentajes habituales ya que entre 1989 y 2019 , tanto las elecciones presidenciales como las legislativas han tenido entre un $93 \%$ y un $99 \%$ de positividad (Ministerio del Interior, 2019). 


\subsection{El kirchnerismo: nueva orientación política y una relación distante}

Después del colapso económico del 2001, Argentina canceló la deuda con el Fondo pagando por adelantado USD\$ 9.800 millones en el año 2006. Desde entonces, el Organismo no tuvo influencia en la política económica nacional. Es más, durante el periodo que va del 2003 hasta el 2015, Argentina fue gobernada por la coalición política de centro-izquierda conocida como "el kirchnerismo" que mantuvo una relación distante y discursivamente conflictiva con el FMI, introduciéndolo como el adversario político, cuyas recetas neoliberales habían destruido la patria (Cotarelo, 2008). El gobierno nacional invirtió la lógica argumentativa desplegada por el Fondo, y el mercado dejó de ser el vértice que garantizaba el ordenamiento social como lo había sido hasta el 2001. El nuevo ordenador pasó a ser el Estado, entendido como el agente reparador de las injusticias sociales del modelo neoliberal. El gobierno se situó dentro del campo popular junto con las organizaciones sociales que habían padecido el avasallamiento de las políticas neoliberales, reivindicando el nacionalismo popular (Martinez, 2013; Retamozo y Di Bastiano, 2017).

De esta forma, se fue consolidando un bloque anti neoliberal con un discurso confrontativo hacia el FMI y se creó un límite entre "nosotros", el pueblo y "ellos", los neoliberales responsables de la catástrofe social (Dagatti, 2013). Esta retórica fue acompañada por políticas sociales asistenciales para las personas desempleadas y dependientes que experimentaban extrema pobreza, bajo los programas de transferencia monetaria condicionada. Estos programas han sido el pivote de la política social posneoliberal, no solo en Argentina, sino también en el resto de Latinoamérica. Durante este periodo, la pobreza y la indigencia se redujeron, generando inclusión a partir de la participación en el mercado. De todas formas, no han sido suficientes para superar las desigualdades estructurales (Nemiña y Echandi, 2020).

A diferencia del menemismo y del gobierno de De la Rua quienes mantuvieron una estrategia confrontativa con los movimientos sociales, el kirchnerismo los integró al diseño de gobierno y en muchos casos sus líderes integraron la administración del Estado. Esto le permitió al gobierno kirchnerista desmovilizar y fragmentar a dichas organizaciones, que durante los 90 se habían mantenido unidas en rechazo a la agenda neoliberal (Dinerstein, 2004; Retamozo, 2011).

A nivel regional, también se consolidó en Latinoamérica un bloque anti neoliberal que se articuló a través del MERCOSUR, en donde se rechazaron las políticas de libre mercado, y las recetas del Fondo. Si bien el MERCOSUR había desarrollado una perspectiva a favor del Consenso de Washington y el regionalismo abierto en su origen (durante la década del 90), el fracaso del proyecto neoliberal dio lugar a un bloque regional que priorizó a las economías nacionales de la región a partir del nuevo siglo (Revelez, 2008). Desde entonces, la región rechazó conjuntamente la iniciativa comercial liberal de Estados Unidos que proponía un Área de Libre Comercio de las Américas (ALCA), y el regionalismo se canalizó a través de la creación de la UNASUR en el 2008 (Jaquenod, 2018).

A partir del 2011, Argentina enfrentó un prolongado estancamiento económico. A su vez, los aliados regionales también comenzaron a tener dificultades para perpetuar sus proyectos políticos. En este marco, el movimiento kirchnerista perdió las elecciones presidenciales del 2015 frente a una coalición de gobierno de centro derecha conocida como "Cambiemos", liderada por el presidente Mauricio Macri. Antes de continuar con el surgimiento del nuevo acuerdo, el próximo apartado discute el rumbo del FMI tras el fallido programa del 2001.

\section{FMI: Crisis de legitimidad y reforma}

Posterior al colapso económico del 2001, la IOE del FMI emitió un comunicado oficial en el que señaló el daño a la reputación del Fondo tras la experiencia argentina y enunció las lecciones aprendidas tras su fallida intervención. Reconoció, entre otras, que el FMI debería haber ejercido una supervisión firme durante el proceso de implementación del Acuerdo con el gobierno argentino y no permitir la implementación de políticas económicas heterodoxas, refiriéndose a las medidas y controles destinados a regular la economía, propias del periodo de agravamiento de la crisis 
económica argentina, a fines del 2001. Además, cuestionó la política económica de la convertibilidad (IOE, 2004).

Desde entonces, Argentina no volvió a solicitar créditos al FMI hasta el 2018. Este alejamiento también se dio en el resto de los Estados latinoamericanos. Algunos autores han señalado que, tras los fallidos acuerdos en la región, el FMI experimentó una crisis de legitimidad, evidenciado en que la región representó menos del 5\% del total de préstamos otorgados después del 2001, lejos del 35\% que había alcanzado en el período 1984-2000 (Jiménez y Lorenzo, 2010; Martone, 2004). Incluso, hay quienes sostienen que el Organismo estuvo cerca de la quiebra (Kentikelenis et al., 2016). De hecho, durante este periodo surgieron varias iniciativas financieras regionales como el Nuevo Banco de Desarrollo, el Banco del Alba, y el Banco del Sur, destinadas a reemplazar el modelo financiero del Fondo (Nemiña y Larralde, 2020). Sin embargo, la crisis financiera global le otorgó al FMI una nueva oportunidad para relegitimarse ya que el G-20 lo dotó de recursos económicos para cooperar en la crisis global. A su vez, el FMI fue reformado al modificar el peso relativo de algunas naciones en el directorio, flexibilizar los requisitos para acceder a algunos créditos y ampliar las líneas de crédito. Al tradicional Stand-by agreement, se sumó la línea de crédito flexible y la línea de precaución y liquidez (Sánchez Pastor y Serra Stecher, 2015).

Varios investigadores han analizado el impacto de las reformas en el Fondo, y la mayoría tiende a ver una continuidad del Organismo en la preferencia por programas de tinte neoliberal, con sutiles modificaciones. Lesage et al. (2013) sostienen que las reformas no fueron suficientes para disminuir la posición privilegiada de los Estados Unidos, su liderazgo y su poder de veto. Nelson (2017), sostiene que desde la reforma no hay evidencia suficiente que contradiga que el FMI privilegia y promueve políticas de corte neoliberal.

En el mismo sentido se encuentran Musacchio (2020) y Kentikelenis et al. (2016) quienes interpretan la reforma como una estrategia del Fondo por legitimar sus programas de ajuste -bajo los conceptos de "aggiornamentos periódicos" e "hipocresía organizada" respectivamente-. Los cambios del Fondo reflejan una nueva fachada organizacional.

Uno de estos cambios discursivos del Fondo consistió en la preocupación creciente por lo social como resultado de las críticas recibidas por los efectos negativos de los programas de ajuste en la pobreza, la indigencia, el desempleo y la desigualdad. Si bien desde 1993, el Fondo incluyó la Red de Seguridad Social y las Estrategias para la Reducción de la Pobreza, estas no lograron ser efectivas. En este contexto, algunos organismos internacionales -principalmente la OIT y UNICEF- promovieron la implementación del "Piso de Protección Social" que es un modelo de política social pensado para garantizar un piso mínimo de bienes y servicios, que se emparenta con las políticas domésticas de transferencias monetarias condicionadas (Nemiña y Echandi, 2020). El Fondo tomó esta demanda y desde 2012, alrededor del $70 \%$ de sus programas incluyeron condiciones ligadas al "Piso de gasto social", que especifican los gastos mínimos en salud, educación y otras políticas sociales (Kentikelenis et al., 2016, p. 561). Sin embargo, la implementación de estos programas careció de falta de metas y casi siempre el "Piso de Gasto Social" se presentó como condición no vinculante. Cuando los gobiernos optaron por no cumplir con estas condiciones, el FMI continuó brindando apoyo financiero ya que el foco se mantuvo en el ajuste fiscal.

De hecho, la experiencia reciente en Europa fue testigo del continuo deterioro de las condiciones sociales de los sectores vulnerables ya que la interpretación de los desequilibrios macroeconómicos tiene como respuesta el ajuste en lo social. Estos programas han seguido teniendo como víctimas a los sectores más desfavorecidos. Esto puede verse en la reforma y el congelamiento de pensiones (en Rumania y Serbia respectivamente), el aumento de la edad jubilatoria de las mujeres en Portugal, o los recortes en el sistema de seguridad griego (Kentikelenis et al., 2016). Por su impacto, este último caso será desarrollado en el próximo apartado. 


\section{1. ¿El FMI cambió? Evidencia del caso griego}

Uno de los antecedentes posteriores a la reforma de mayor relevancia, fue la serie de rescates económicos a Grecia a partir del 2009, por USD \$30.000, el préstamo más alto hasta ese entonces. La crisis financiera global del 2008, había puesto de manifiesto la insolvencia del elevado endeudamiento público y privado de Grecia. En ese contexto, el FMI junto con la Unión Europea firmaron un programa con condicionalidades en el 2010 para garantizar el pago de los vencimientos de su deuda. El programa se apoyó fuertemente en el ajuste estructural y las privatizaciones dado que Grecia no podía devaluar para mejorar su competitividad y restablecer el equilibrio externo, ya que pertenece al Euro, un área monetaria única (Amor y Echeverria, 2015). De este modo, el Fondo confirmó su agenda económica tradicional.

Si bien el programa fue exitoso ya que logró su objetivo de rescatar a los acreedores griegos y evitar la ruptura de las instituciones monetarias europeas, tuvo consecuencias sociales negativas (Pénet, 2018). En 2013, el desempleo llegó al 27.9\% mientras que el desempleo juvenil fue del $60 \%$. Además, conllevó un severo recorte del sistema de seguridad social y la salud de la población griega se vio deteriorada como consecuencia de estas medidas de austeridad (Kentikelenis et al., 2014). Esto fue controversial, ya que, pese a sus esfuerzos discursivos, una vez más el Fondo demostró indiferencia por los efectos sociales de sus recetas.

Así como sucedió en Argentina en el 2001, el deterioro de las condiciones de vida de los sectores impactados por el programa de ajuste sin ningún tipo de red asistencial, provocó insurrecciones civiles y el surgimiento de nuevos movimientos sociales, que se sumaron a los ya existentes (Petropoulou, 2015). No es casual que, frente a los niveles de desempleo y desempleo juvenil, surgieran nuevos movimientos de los sectores trabajadores y estudiantes universitarios con consignas asamblearias y de autogestión. De esta manera, los movimientos sociales se alejaban de los canales políticos tradicionales. En este contexto, varios gobiernos de distinto signo político debieron adelantar elecciones y convocar referéndums para la toma de decisiones frente a la deuda. Mientras que los gobiernos que estaban dispuestos a realizar el ajuste se enfrentaban con la resistencia social, aquellos que intentaron suspender las recetas del Fondo debían hacer frente a una crisis económica sin recursos. En ambos casos, las autoridades se enfrentaron con serias dificultades para gobernar.

La agenda del ajuste sin políticas sociales comprueba la continuidad de la agenda tradicional del Fondo. A su vez, sirve como antecedente - junto al caso argentino del 2001-para comprender que asegurar la gobernabilidad es un requisito para la implementación de los programas de ajuste y con ello, resulta necesario evitar su obstaculización. Contener a los impactados es indispensable para dar continuidad a la agenda del Fondo.

\section{El resurgimiento del bloque neoliberal en Argentina y la vuelta del FMI}

A partir de la asunción del macrismo en el 2015, el gobierno fue capaz de restaurar la agenda neoliberal a partir de la consolidación de una alianza entre actores locales e internacionales (Varesi, 2016; Bona, 2019). En la esfera doméstica, el gobierno consolidó su hegemonía con los medios de comunicación, logrando tener un "blindaje mediático" y estigmatizando a los políticos del gobierno anterior, al vetar la ley 26.522, conocida como ley de Medios. Esta ley había sido impulsada por el gobierno kirchnerista y prohibía la concentración de medios, lo que directamente impactaba sobre el principal multimedio de la Argentina, el Grupo Clarín. Por otra parte, el Gobierno Nacional eludió al Senado, y nombró por decreto a los miembros de la Corte Suprema de Justicia, decisión que fue cuestionada por su inconstitucionalidad (Carranza, 2016). Posteriormente, el gobierno fue beneficiado políticamente por las causas judiciales que activó el Poder Judicial en relación al gobierno anterior. A diferencia del 2001 cuando la Justicia había obstaculizado las reformas propuestas por el FMI, durante el macrismo los esfuerzos de la Justicia federal se concentraron en causas judiciales vinculadas a la corrupción de los ex funcionarios kirchneristas, incluida la ex presidenta Cristina Fernández de Kirchner (Katz, 2017). 
En el escenario internacional, Argentina cambió su posición geopolítica, al alejarse de la integración latinoamericana, de China y Rusia, y al consolidar una nueva alianza con los Estados Unidos. El nuevo gobierno intentó sin éxito reflotar el viejo proyecto del ALCA, se adhirió a la Alianza del Pacífico como observador y promovió acuerdos de libre comercio con la Unión Europea (Morgenfeld, 2017). A su vez, junto a otros cinco países suspendió su participación en UNASUR y desplegó una estrategia confrontativa con su ex socio Venezuela (Varesi, 2016).

El programa económico pro-mercado del macrismo estaba enfocado en reducir el déficit fiscal a partir de la disminución del gasto público, pero manteniendo los programas de asistencia social creados durante el kirchnerismo (Natanson, 2019). Mientras tanto, el déficit sería financiado con crédito externo. Dicha estrategia era avalada por los repports del FMI en 2016 y 2017 que cuestionaban la herencia recibida del gobierno previo (Bonavida et al., 2018). A comienzos del 2018, la suba de la tasa de interés de los Estados Unidos y el fortalecimiento del dólar americano provocó que los prestamistas retiraran su dinero de los países en desarrollo (Druck et al., 2018). Al igual que en la década de los 90 , los cambios internacionales una vez más hicieron tambalear el programa político económico.

Frente a la falta de financiamiento externo, se inició una acelerada fuga de capitales en mayo del 2018, lo que motivó las negociaciones con el Fondo (Cuattromo, 2018). En ese entonces, el FMI solicitó descartar la estrategia gradualista y acelerar el ajuste (IMF, June 2018; Ministro de Hacienda, 2018).

El 8 de mayo del 2018, el Ministro de Finanzas Dujovne comunicó la formalización de la negociación entre Argentina y el Fondo para la implementación de un nuevo acuerdo. Para esto, el gobierno tuvo que marcar un quiebre, al menos discursivo, con la previa intervención del FMI que finalizó con el colapso económico del 2001. El ministro se refirió al Fondo sosteniendo que "estamos hablando de un FMI muy diferente del que conocimos hace 20 años. El FMI ha aprendido del pasado y es muy distinto" (Casa Rosada, 8/5/2018: min 5:55). Sin embargo, no hubo manifestaciones explícitas que detallasen de qué se trató ese cambio. Lo que queda claro es que, en el contexto de acelerado endeudamiento argentino, el Fondo tuvo una nueva oportunidad para promover sus créditos en la región y demostrar qué hay de nuevo en este periodo de endeudamiento. Antes de centrar esta investigación en el nuevo acuerdo, es conveniente señalar cómo llega el FMI al nuevo acuerdo y evaluar las transformaciones que sufrió el Organismo.

En junio del 2018, Argentina finalmente sancionó el Acuerdo Stand-by por USD\$50 mil millones, el crédito más grande jamás otorgado en la historia del FMI. En relación a la deuda, este préstamo es comparativamente más alto que los anteriores ya que representó el $15.6 \%$ del total de la deuda pública, mientras que, en el siglo XX, representaba entre el $4 \%$ y $5 \%$, con solo picos de $7 \%$ y $9 \%$ en 1956-1959 y 2000-2002. Del total del préstamo, el Acuerdo aseguraba que la mitad sería utilizada para el presupuesto nacional y la otra mitad sería precautorio (IMF, June 2018).

El principal objetivo del programa de ajuste era reducir el déficit fiscal que se consideraba la causa principal de los problemas económicos nacionales (Cuattromo, 2018). Las historias causales que sustentan el Acuerdo expresan las coincidencias políticas y económicas entre el gobierno macrista y el FMI. Este último resaltó las políticas adoptadas hasta ese entonces por la coalición de gobierno "Cambiemos", tendientes a la desregulación de la economía y celebró la quita de subsidios a la energía, la unificación del tipo de cambio, y la no intervención estatal en el valor de la moneda (IMF, June 2018, p. 4-5).

Además, sostuvo que la crisis argentina respondía a la combinación entre la "herencia" recibida por parte del gobierno kirchnerista que había mantenido inconsistencias macroeconómicas y distorsiones microeconómicas, y la falta de crédito externo por la suba de la tasa de interés de Estados Unidos. Esto había afectado el buen desempeño que el país había comenzado a transitar hacia fines del 2015 y que por lo tanto se instaba a que el gobierno mantuviera la dirección políticoeconómica, pero que acelerara el ajuste. 


\subsection{El contenido del Programa}

El Acuerdo Stand-by firmado en 2018, es un programa de ajuste basado en cuatro pilares. El primer pilar era el fiscal. El ajuste del gasto fue presentado como la solución para restaurar la confianza del mercado. Al hacer esto, el FMI preveía que Argentina crecería económicamente de manera equitativa y consolidaría la creación de empleo (IMF, june, 2018; Annex p. 3). El segundo pilar era el bancario. El objetivo de este pilar fue fortalecer la credibilidad del Banco Central utilizando metas de inflación. En tercer lugar, estaba el pilar comercial, que pretendía disminuir progresivamente las tensiones en la balanza de pagos al reforzar la confianza del mercado.

Por último, se presentó el nuevo pilar social. A diferencia del acuerdo previo donde la seguridad social era la variable de ajuste, en este nuevo acuerdo el gasto social fue garantizado por el FMI para proteger a los más vulnerables. El Fondo reconocía que el programa tendría un impacto en los más pobres y por ello, promovió el fortalecimiento de las redes vigentes de contención social y, a su vez, pretendía reducir la desigualdad de género (IMF, June 2018). Mientras que los primeros tres pilares confirman la lógica tradicional del Fondo en favor de la desregulación de la economía, el cuarto pilar aparece como novedoso. Sin embargo, es el único pilar que carece de condicionalidades. Esto implica que el Fondo no cuenta con mecanismos para hacer cumplir las referencias hacia la población vulnerable (Bonavida et al., 2020).

\subsection{Repitiendo "viejos errores" en el proceso de implementación}

Si bien el Acuerdo inicial fue por USD\$ 50.000 millones, 3 meses después de entrado en vigencia, el mismo fue extendido a USD\$ 57 millones y Argentina fue autorizada a utilizar la totalidad del crédito para el presupuesto, sin necesidad de disponer recursos precautorios (IMF, October 2018). Esta modificación marcó el comienzo de una fase de supervisión laxa donde Argentina pudo mantener la vigencia del Acuerdo mientras lo modificó en varias oportunidades y no cumplió con algunos de los objetivos propuestos. En primer lugar, Argentina violó el Artículo 6 del Acuerdo constitutivo del FMI al utilizar créditos del Fondo para hacer frente a una salida substancial o continua de capitales - más conocido como "fuga de capitales" (Fondo Monetario Internacional, 2011, p. 21) (Ver gráfico 1).

Gráfico 1. Flujo de activos. Entrada y salida de capitales junio 2018 a julio 2019

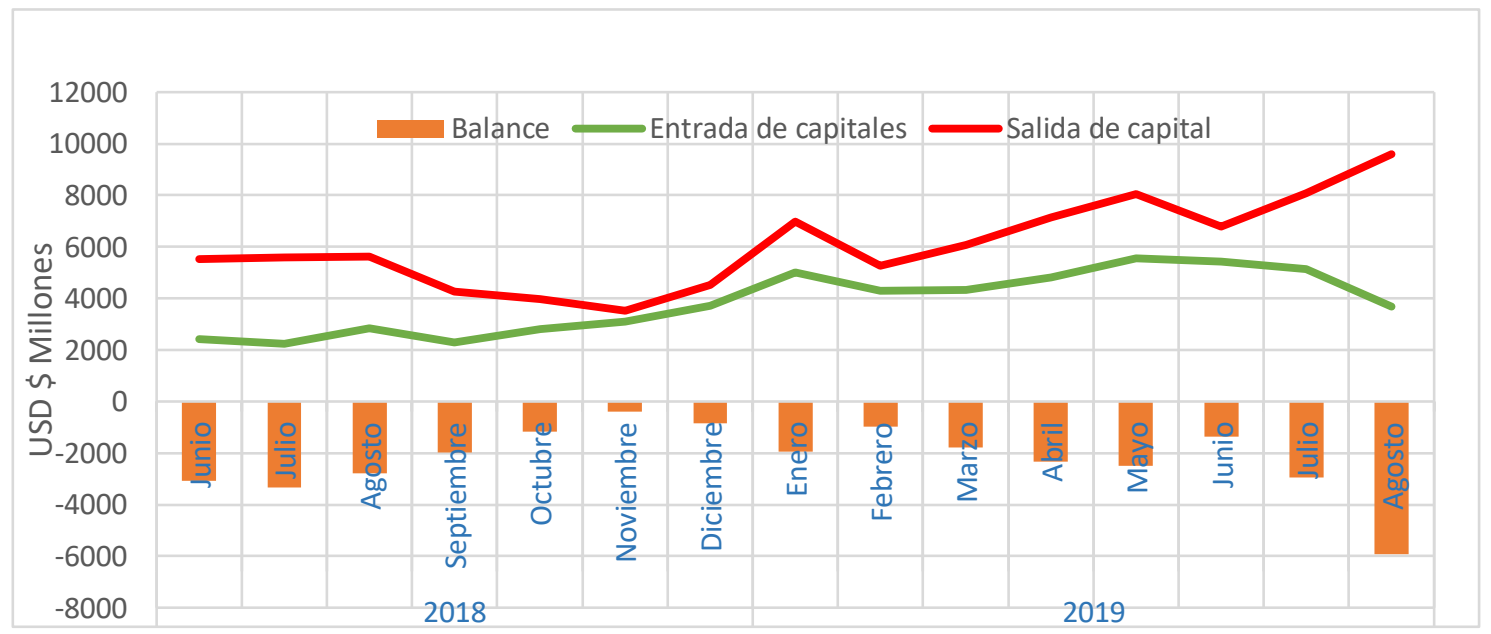

Fuente: Elaboración propia. Datos del Banco Central de la República Argentina

Por otro lado, violó una directriz del Acuerdo, al vender USD\$ 302 millones de reservas del Banco Central en el mercado de divisas el 27 de agosto del 2019, cuando el máximo permitido era de USD\$ 250 millones por día.

En cuanto a la supervisión laxa, el Fondo aceptó alterar el cronograma de desembolsos y adelantar las cuotas del crédito, de modo tal que el $78 \%$ del crédito fuese depositado antes de las elecciones nacionales en Argentina cuando estaba pautado que para esa fecha se habría depositado 
el 53\% (IMF, October 2018). Cabe señalar que la discrecionalidad para modificar los desembolsos previos a las elecciones nacionales beneficiando al oficialismo tiene una connotación política.

Por otro lado, el FMI aceptó eliminar las metas de inflación (IMF, October 2018). Si bien en el Acuerdo original, el pilar bancario había destacado que cumplir las metas de inflación provocaría previsibilidad en la economía argentina, el aumento incontrolado provocó que dichas metas debieran ser desterradas. Por ejemplo, para el año 2018, el Fondo había previsto que la implementación del programa produciría una inflación del $27 \%$ anual, aunque finalmente la misma fue de $47.6 \%$. Lo mismo sucedió con las predicciones para el 2019, cuando el Fondo había previsto una inflación del $17 \%$, que finalmente fue del $53.8 \%$, la más elevada en los últimos 28 años (INDEC, 2019).

Durante el 2019, la crisis económica continuó profundizándose. Tal es así que la Organización de Empresarios Nacionales Argentinos sostuvo que, durante el primer cuatrimestre del 2019, cerraron en promedio 60 pequeñas y medianas empresas por día (ENAC, 2019). En este contexto, el FMI autorizó a la coalición de gobierno a modificar primero y eliminar después los límites de la banda de cambio flotante (IMF, April 2019). A su vez, el Fondo autorizó al gobierno a implementar políticas para el control de precios en los alimentos, descuentos en planes de medicamentos, planes para pequeñas empresas y otros subsidios para la importación de insumos básicos. Por último, en julio del 2019, el FMI otorgó un waiver a Argentina cuando el gobierno no presentó la información requerida en el día asignado (IMF, July 2019). Estos cambios durante el proceso de implementación y las medidas económicas adoptadas contradicen las lecciones aprendidas del FMI enunciadas por la IOE en el 2004 respecto a mantener un firme monitoreo (IOE, 2004).

\section{3. ¿Protegiendo a los más vulnerables? Reempaquetado las redes de seguridad social}

Como se mencionó más arriba, una de las novedades del nuevo acuerdo consistió en la consideración de los sectores vulnerables a través del pilar social. Este no implicó la inclusión de nuevos programas ni modificó la lógica de los programas vigentes. Simplemente se apoyó en las redes de seguridad social locales: el Programa para la primera infancia (instalaciones públicas para el cuidado infantil), el seguro de desempleo, la Asignación Universal por Hijo (AUH) y la Asignación Universal para Embarazo (AUE). La mayoría son programas de transferencia monetaria condicional y habían sido creados durante el gobierno kirchnerista.

Sin embargo, los programas sociales por sí solos no son suficientes para evitar la pobreza ni la indigencia ya que el poder de compra per cápita es mínimo. Por ejemplo, uno de los programas de desempleo que otorga uno de los ingresos más alto es el "Salario Social Complementario", que comprende el $50 \%$ del salario mínimo vital y móvil. Para percibir este ingreso, la persona debe ser económicamente activa y desempleada. El ingreso percibido por este programa de desempleo representaba en el 2018 tan solo el 66\% de los ingresos per cápita necesarios para sobrepasar la línea de indigencia, lo que significa alcanzar la canasta básica de alimentos. Otro programa importante por su extensión y efectos educativos es la AUH, que en el año 2019 otorgaba pagos mensuales de 2.652 pesos argentinos (USD \$ 44 en ese momento) a las madres por cada hijo. Esto solo representaba el $40 \%$ del ingreso per cápita necesario para acceder a la canasta básica de alimentos y solo el 17\% de los ingresos necesarios para alcanzar la línea de pobreza (INDEC, 2020b).

Durante el gobierno de "Cambiemos", se deterioró la capacidad de compra de estos programas (Weisbrot y Merling, 2018). El aumento de los salarios y asignaciones siempre ha estado por debajo del aumento de la inflación. A su vez, el rubro alimentos ha liderado los aumentos, hecho que directamente impacta sobre los sectores más vulnerables y dificulta el acceso a la canasta básica de alimentos. Por ejemplo, entre diciembre 2018 y diciembre 2019, la inflación total interanual fue del 53.8\%, mientras que los alimentos aumentaron el 56.8\% (INDEC, 2020a). Esto ha tenido un impacto en la pobreza. Desde que inició el gobierno, el índice de pobreza ha tenido una tendencia positiva, hecho que se aceleró a partir de la firma del nuevo acuerdo con el 
Fondo. Tuvo un incremento de más de un $8 \%$, pasando del $27.3 \%$ en el primer semestre del 2018 al $35.5 \%$ en el segundo semestre del 2019 (ver tabla 1).

Tabla 1. Evolución de la pobreza argentina desde el 2016

\begin{tabular}{|c|c|c|c|c|c|c|c|c|}
\cline { 2 - 8 } \multicolumn{1}{c|}{} & \multicolumn{2}{c|}{2016} & \multicolumn{2}{c|}{2017} & \multicolumn{2}{c|}{2018} & \multicolumn{2}{c|}{2019} \\
\hline Semestre & I & II & I & II & I & II & I & II \\
\hline Tasa de pobreza & 31,4 & 30,3 & 28,6 & 25,7 & 27,3 & 32 & 35,4 & 35,5 \\
\hline
\end{tabular}

Fuente: Elaboración propia a partir de los datos del INDEC, 2020b

Lo mismo sucedió con la desigualdad. El coeficiente de Gini se deterioró el 2.8\% pasando del 0.422 en el segundo cuatrimestre del 2018 al 0.434 en el segundo cuatrimestre del 2019. Para ese año, el decil más rico tuvo un ingreso promedio 23 veces más grande que el $10 \%$ más pobre. Un año antes, esta diferencia era de 21 (INDEC, 2020c). Si bien estos resultados no son atribuibles exclusivamente al Acuerdo con el FMI, ya que en todo caso el Fondo continuó o aceleró una tendencia preexistente, es evidente que el pilar social no ha sido suficiente para revertirla.

Para ser elegible por el pilar social, esto es, percibir los "beneficios" de las redes de asistencia social, primero hay que ser excluido del sistema laboral formal. La lógica del pilar social no consiste en promover el trabajo o evitar la pobreza, sino en contener a aquellos afectados por la agenda económica introducida. En este contexto, la red de seguridad social en la que se apoya el nuevo acuerdo funciona ex post, una vez que las personas caen en la pobreza y/o el desempleo. La contención, que aparece como un mecanismo posterior a la exclusión, minimiza las posibles reacciones de los afectados y busca garantizar la continuidad de la agenda neoliberal al generar una dependencia con los excluidos. Su posible reacción está condicionada por la dependencia del Estado y esto puede producir un consenso forzado, reduciendo la radicalización de las protestas. Esto marca una verdadera ruptura con el 2001 y con la experiencia griega en el 2009, cuando los excluidos del proyecto fueron ignorados por la agenda del ajuste. En ese entonces, los sectores damnificados se organizaron a través de los movimientos sociales y resistieron en las calles el avasallamiento del neoliberalismo. Incluso, como se mencionó más arriba, la indiferencia del Estado por sobre ciertos sectores provocó que el sistema político atravesara una crisis de representatividad y que peligrara la gobernabilidad.

En este sentido, parece ser que, en el nuevo acuerdo, el Fondo se ha obligado a no desoír a aquellos que su propio programa expulsa. Sin embargo, el limitado alcance económico de los programas de asistencia social amenaza el consenso con los más vulnerables.

\subsection{Impacto de los programas de ajuste en las mujeres}

Antes de desarrollar el contenido de la perspectiva de género, se debe tener en cuenta el impacto de los programas de ajuste en las mujeres. Ellas resultan sus principales víctimas, ya que son el eslabón más débil del mercado laboral. En contextos recesivos en los que las familias deben asumir la responsabilidad del cuidado familiar frente a la imposibilidad económica de tercerizar tareas en el mercado, son las mujeres las que asumen estas tareas. Esto empobrece principalmente su tiempo al aumentar sus funciones no remuneradas y son las primeras en renunciar al mercado laboral si las tareas de cuidado están insatisfechas (Sainz, 2017; Bittman, 2015). Su pérdida del empleo también conlleva la pérdida de su independencia económica (Dalessandro, 2018).

Otra consecuencia de los programas de ajuste en el género proviene de la experiencia previa en Argentina con el Fondo durante los 90. Hacia finales de la década, aumentó significativamente la trata de explotación sexual y se consolidaron de las redes de prostitución, como consecuencia de la crisis económica (Naddeo, 2015). La experiencia indica que la interseccionalidad entre género y pobreza ha oprimido particularmente más a las mujeres pobres. 


\subsubsection{Equidad de Género: voluntarismo y financiamiento limitado}

En el Acuerdo Stand-by, el FMI definió a las mujeres como parte de la población vulnerable e incentivó al gobierno nacional a que incrementara la participación del trabajo femenino (IMF, June 2018, p. 4). Desde que el Acuerdo entró en vigencia, el gobierno tomó medidas para desarrollar un sistema voluntario para calificar a las empresas en sus políticas de género y proporcionó recomendaciones para garantizar la igualdad de oportunidades en el lugar de trabajo (IMF, December 2018, p. 11). Sin embargo, la efectividad es cuestionable ya que el programa es meramente informativo y carece de exigibilidad.

Por otro lado, el Fondo celebró la ampliación de las instalaciones públicas de cuidado infantil ya que consideraba que esto serviría para ayudar a aumentar la participación femenina en la fuerza laboral y nivelar sus oportunidades, especialmente a los hogares de bajos ingresos (IMF, October, 2018, p. 12). Además, el Fondo aprobó la extensión de los programas sociales vigentes para madres desempleadas (como AUH y AUE).

El enfoque asistencial que propone el Acuerdo a través de las redes vigentes es problemático ya que el apoyo a las mujeres se da solo por su figura reproductiva (Arriagada, 2005. p. 109). La asistencia estatal se obtiene solo a través de la figura de la mujer madre ya que no existen políticas dirigidas a mujeres que no sean madres, lo que revela una suposición implícita de que su vulnerabilidad en el mercado laboral es el resultado de la maternidad. Estos programas no interpretan que las mujeres tienen dificultades para acceder al empleo no solo porque son madres sino también porque son mujeres. Al mismo tiempo, algunos investigadores han argumentado que tanto la AUH como la AUE, que priorizan a las madres en lugar de los padres, reproducen las desigualdades de género ya que refuerzan la idea de que las mujeres son, como madres, las principales responsables de las tareas de cuidado familiar (Pautassi et al., 2014). Las madres acceden a la seguridad social a través de sus hijos y esto las reduce a las tareas domésticas.

En segundo lugar, las políticas de asistencia social implementadas desde una perspectiva de género, consolidan la lógica del pilar social de contención después de la exclusión. No existen políticas condicionales de prevención o promoción para fortalecer la posición de las mujeres en relación con los hombres en el mercado laboral. La nula efectividad de la perspectiva de género en el Acuerdo puede corroborarse a partir del crecimiento de la tasa de desempleo en las mujeres (ver tabla 2). Desde que se sancionó el nuevo préstamo, este índice ha aumentado de manera estable tanto para las mujeres como para los hombres, sin cambios significativos en la tendencia que coloca a las mujeres argentinas con un porcentaje de desempleo mayor que los hombres. Debe tenerse en cuenta que estos índices no incluyen a aquellas mujeres que renuncian al mercado laboral por tener que reasumir las tareas de cuidado y que, por lo tanto, dejan de estar en una búsqueda activa.

Tabla 2: Evolución del desempleo en Argentina desde el 2017

\begin{tabular}{|c|c|c|c|c|c|c|c|c|c|c|}
\cline { 2 - 12 } \multicolumn{1}{c|}{} & $\mathbf{2 0 1 7}$ & \multicolumn{4}{|c|}{2018} & \multicolumn{4}{c|}{2019} & $\mathbf{2 0 2 0}$ \\
\hline Semestre & IV & I & II & III & IV & I & II & III & IV & I \\
\hline Tasa de desempleo total & 7,2 & 9,1 & 9,6 & 9 & 9,1 & 10,1 & 10,6 & 9,7 & 8,9 & 10,4 \\
\hline $\begin{array}{c}\text { Tasa de desempleo } \\
\text { varones }\end{array}$ & 6,1 & 8 & 8,7 & 7,8 & 8,2 & 9,2 & 10,2 & 8,9 & 8,4 & 9,7 \\
\hline $\begin{array}{c}\text { Tasa de desempleo } \\
\text { mujeres }\end{array}$ & 8,7 & 10,6 & 10,8 & 10,5 & 10,2 & 11,2 & 11,2 & 10,8 & 9,5 & 11,2 \\
\hline $\begin{array}{c}\text { Tasa de desempleo } \\
\text { mujeres de 14 a 29 años }\end{array}$ & 18,8 & 20,9 & 21,5 & 21,5 & 21,4 & 23,1 & 23,4 & 22,6 & 18,9 & 23,9 \\
\hline
\end{tabular}

Fuente: Elaboración propia a partir de los datos del INDEC, 2020d 


\subsection{2. ¿Por qué el género? Penetrando en la Agenda Local}

Frente al escaso contenido y resultado en materia de género, cabe preguntarse ¿A qué responde que el FMI incluya en su agenda temas sin ningún tipo de consecuencia práctica? Esta pregunta fue respondida de manera parcial previamente, al señalar que el Fondo introduce cambios en sus programas según el cuestionamiento de los mismos. Esto explicó la inclusión de la Red de Seguridad Social o las Estrategias para la Reducción de la Pobreza.

A su vez, se debe tener en cuenta que el Fondo también toma temas de interés de los Estados de la periferia para penetrar en la agenda nacional y mejorar su capacidad de influencia, lo que le permite posteriormente legitimar sus políticas de ajuste.

En los últimos años, el Fondo ha manifestado un interés creciente por temas vinculados a la corrupción y el cambio climático. Ha impulsado la iniciativa de "Buen Gobierno" en la que tomó como interés la lucha contra la corrupción, que es un tema de alto impacto en los países en desarrollo. De ese modo, buscó asimilar a las élites locales y consolidar un bloque histórico transnacional más amplio, compartiendo los supuestos y los intereses de clase de las fracciones dominantes (Taylor, 2004). Lo mismo sucedió con la preocupación creciente del Fondo por la inequidad que refleja una fachada organizacional (Forster et al., 2019). Si bien, la retórica del Organismo se ha centrado en este tema, sus intervenciones continúan provocando un incremento en la desigualdad (Lang, 2006). Esto explica por qué el Fondo ha actualizado y sofisticado su discurso al incluir nuevos conceptos como "participación", "empoderamiento" o "reducción de pobreza", pero que carecen de contenido. Estos términos son introducidos a través de un discurso apolítico y sin consecuencias prácticas (Cornwall \& Brock, 2005).

En este contexto se entiende que el Fondo se apoye sobre un tema relevante en la agenda argentina, como es el género. En los últimos años, el movimiento feminista y las cuestiones de género han adquirido mayor relevancia.

Algunas de las consignas del movimiento feminista han sido respaldadas durante el kirchnerismo. Hubo avances en la inclusión de la perspectiva de género en la legislación, en las políticas públicas y se han desarrollado algunas normativas de regulación de las relaciones laborales, incluyendo la sanción de la ley del cupo femenino (Aspiazu, 2014; Di Marco, 2010). Si bien en materia de derechos el kirchnerismo estuvo identificado con políticas progresistas ya que reivindicó derechos de diversidad sexual, como la aprobación de leyes como matrimonio igualitario e identidad de género, también ha sido cuestionado por no poner sobre la agenda política temas como el aborto (Tabbush et al., 2016).

Durante el macrismo, el movimiento feminista continuó activo logrando mantener encendido el reclamo sobre la violencia de género través de la campaña "Ni una menos" que buscaba visibilizar a las víctimas de femicidios (Natalucci y Rey, 2018), y logró que finalmente el Poder Legislativo discutiera la legalización, seguridad y gratuidad del aborto en el año 2018 aunque el proyecto fue finalmente rechazado por el Senado (Acosta, 2020). En este sentido, se entiende que el FMI haya incorporado en su programa un tema relevante en la agenda local para legitimar el Acuerdo. De todas formas, como se demostró en el apartado anterior, el modo en el que se inscribe la perspectiva de género es estéril.

\section{El "débil" pilar social como transformismo}

La crisis económica argentina en el 2001 cuestionó el liderazgo moral e intelectual de la agenda neoliberal. A nivel nacional, el gobierno fue incapaz de continuar con las políticas de ajuste propuestas por el Fondo al no contar con el acompañamiento de la Justicia y al enfrentar la resistencia de los movimientos sociales en las calles, como consecuencia de la pobreza y desigualdad crecientes. Como respuesta al fracaso de este proyecto económico, se consolidó un bloque contrahegemónico entre el 2003 y el 2015 cuya orientación política reivindicó el rol activo del Estado, la regulación de la economía, y desarrolló políticas públicas tendientes a la redistribución del ingreso y, además, tomó algunas consignas del movimiento femenino. 
Sin embargo, el estancamiento económico del 2011, junto con la progresiva desintegración de la alianza regional, le otorgó al neoliberalismo una nueva oportunidad para reintroducirse en la política argentina. Como se mencionó más arriba, a partir del 2015, se consolidó una nueva alianza estratégica compuesta por el gobierno local, los medios de comunicación, el Poder Judicial y Estados Unidos, en búsqueda de reintroducir políticas pro mercado en el país. A solo dos años de que el nuevo ciclo político-económico se iniciara, el programa demostró ciertos límites como consecuencia de los cambios en el mercado internacional.

En este escenario, el FMI apareció como un agente clave para reafirmar la dirección económica y fortalecer el nuevo consenso. Su condición de prestamista junto con su capacidad para influenciar al mercado financiero le permitía al gobierno enfrentar la crisis económica frente a la ausencia de crédito externo privado. En este sentido, el FMI desembolsó el préstamo más grande jamás otorgado y convalidó la orientación político-económica del gobierno al ratificar el rumbo elegido.

Sin embargo, la reintroducción del FMI no podía hacerse sin antes resolver la crisis de legitimidad tras la fallida experiencia del 2001. Para eso, el Fondo debía mostrar una ruptura con la intervención pasada. A través del pilar social, el FMI aplicó la estrategia de transformismo, que consistió en incorporar tanto a los pobres como a las mujeres en el Acuerdo.

Por un lado, el pilar social le sirvió como método de auto legitimación, ya que le otorgó al Organismo la posibilidad de diferenciarse de su última aparición. Si en el 2001 lo social había sido la variable de ajuste, en el 2018 el pilar social expresa una aparente comprensión y compromiso con los más vulnerables. Así, el FMI intentó acercarse a la agenda popular, y entrar en contacto con los amplios sectores que históricamente habían sido ignorados, en búsqueda de un consentimiento alrededor de su nuevo programa de ajuste.

Por otro lado, el pilar social le permitiría al Fondo contrarrestar los avances contrahegemónicos, ya que se acercaba a un sector popular profundamente identificado con el gobierno kirchnerista: los sectores vulnerables. Al asimilar las demandas de los opositores en los propios programas y discursos, se buscó desarticular y debilitar a la resistencia opositora.

Por último, la lógica del pilar social basada en la contención pos exclusión (a través de la extensión de las redes de asistencia social) buscó garantizar la gobernabilidad. Los programas de asistencia social permitirían contener a los excluidos y, de ese modo, evitar que los sectores vulnerables sean obstáculo para la implementación de la agenda del ajuste como lo fueron en el 2001, y en el 2009 en Grecia. La lógica que subyace al pilar social es que la dependencia del sector vulnerable con el Estado disminuiría su capacidad de resistencia. Conceptualmente, la inclusión de los vulnerables en el Acuerdo representa un intento por asimilar y domesticar contrapartes potencialmente peligrosas y reforzar el bloque neoliberal hegemónico.

Sin embargo, como se ha demostrado, el alcance económico del pilar social es limitado ya que su capacidad de contención es mínima y esto pone en jaque la alianza con los "vulnerables". Hasta el momento, el proyecto neoliberal ha traído una vez más, desigualdad, desempleo y pobreza, y esto ha sido contestado por aquellos destinados a ser contenidos. Desde que se firmó el nuevo acuerdo, varios actores han cuestionado el renovado programa de ajuste. Distintas capas de la clase obrera que se encontraban divididas antes del macrismo, comenzaron a unificarse en las protestas a partir del deterioro económico y el nuevo acuerdo con el Fondo, consolidando el bloque contrahegemónico (Carrera et al., 2020). Los sindicatos, los partidos políticos de izquierda y centro izquierda, los movimientos sociales locales y la ONG internacional la vía campesina, han tomado las calles bajo el lema "el país está en peligro" (La Vía Campesina, 2018; Slimovich, 2017). Al mismo tiempo, la Iglesia ${ }^{1}$ y los científicos argentinos ${ }^{2}$ han tenido una actitud de confrontación

\footnotetext{
${ }^{1}$ La Iglesia criticó el regreso al FMI: "No es una salida inteligente". Economía Perfil, 11 de mayo de 2018. Recuperado de: https://www.perfil.com/noticias/economia/un-obispo-de-la-conferencia-episcopal-criticoel-acuerdo-con-el-fmi.phtml

2 Científicos contra las recetas del FMI. Página 12, 29 de mayo de 2018. Recuperado de: https://www.pagina12.com.ar/117943-cientificos-contra-las-recetas-del-fmi
} 
frente al nuevo acuerdo. El alcance de la agenda neoliberal "aggiorrnada" con su débil pilar social parece definitivamente haber entrado en crisis tras los contundentes resultados en las urnas durante las elecciones presidenciales a finales del 2019, que han dado como presidente al candidato de una nueva coalición de gobierno integrada mayoritariamente por un "renovado" kirchnerismo.

\section{Conclusión}

Esta investigación comenzó preguntándose qué aprendió el FMI tras la experiencia fallida del 2001. En 2004, la IOE respondió a esta pregunta argumentando, entre otros motivos, que la falta de supervisión firme había sido uno de los principales errores del Fondo. Sin embargo, como se ha demostrado, durante la implementación del nuevo acuerdo del 2018, el FMI volvió a mantener una supervisión laxa. Desde una perspectiva neogramsciana, esta investigación ha demostrado que el Fondo aprendió que, para reforzar el consenso neoliberal en la Argentina, los sectores vulnerables no podían ser ignorados como lo fueron en el 2001 o como lo fueron en Grecia a partir del 2009. Durante la renovada era del ajuste iniciada en el 2015 y ratificada por el Fondo en el 2018, solamente la asistencia social sobrevivió y esto es porque el FMI aprendió de su experiencia previa que, sin una protección social mínima, el neoliberalismo correría el riesgo de que un brote social pausara su agenda.

Si bien los resultados económicos no pueden ser atribuidos exclusivamente al FMI, hasta entonces su aporte económico ha venido a convalidar, una vez más, el crecimiento de la pobreza, desigualdad y desempleo. Esto ha producido un descontento social creciente que pone en jaque la continuidad de la orientación político-económica de dicho programa ya que el alcance del pilar social fue limitado.

\section{Referencias bibliográficas}

Acosta, M. (2020). Activismo feminista en Instagram. El caso de la Campaña Nacional por el Derecho al Aborto Legal Seguro y Gratuito en Argentina. Perspectivas de la comunicación, 13(1), pp. $29-46$

Amor, J. M. y Echeverria, V. (2015). Grecia: El Papel de las Instituciones Europeas y el FMI en la Crisis. En F. Fernández Méndez de Andés (dir.), Anuario del Euro 2015. Fundación de Estudios Financieros (pp. 227-247). Recuperado de: https://www.researchgate.net/profile/Carlos_Poza/publication/297026156_Anuario_del_euro_2 015/links/56dca64908aebabdb4142765.pdf\#page $=227$

Arriagada, I. (2005). Dimensiones de la pobreza y políticas desde una perspectiva de género. Revista de la CEPAL, 85, pp. 101-113

Aspiazu, E (2014). Equidad de género, mercado de trabajo y sindicalismo en la Argentina. Realidad Económica (Instituto Argentino para el Desarrollo Económico), 284, pp. 10-36

BCRA (2020). Informe de la Evolución del Mercado de Cambios y Balance Cambiario. Banco Central de la República Argentina. Recuperado de: http://www.bcra.gov.ar/PublicacionesEstadisticas/Mercado_de_cambios.asp

Bittman, M. (2015). Working time. In S. Edgell. E. Granter, \& H. Gottfried (Eds.), The SAGE handbook of the sociology, work \& employment (pp. 520-540). SAGE

Blanchard, O., Dell'Ariccia, G., \& Mauro, P. (2010). Rethinking Macroeconomic Policy. IMF Staff Position Note. International Monetary Fund. Research Department. SPN/10/03 
Bona, L. M. (2019). ¿Neoliberalismo hegemónico? Apuntes sobre el Estado, el bloque de poder y la economía política en la Argentina reciente (2016-2018). Revista Pilquen. Sección Ciencias Sociales, 22(1), pp. 39-54

Bonavida, C., Gevaerd Bernal, P., González Obregón, L., Dikstein, B., Kutnich, J., Velazquez, H. y Nemiña, P. (2018). Argentina y el FMI: análisis de un nuevo acuerdo. Chaco: Escuela de Gobierno. Recuperado de: http://www.escueladegobierno.chaco.gov.ar/files/documentos-detrabajo/informe-endeudamiento-fmi.pdf

Brenta, N. L. (2011a). Argentina y el FMI: efectos económicos de los programas de ajuste de larga duración. Anuario del Centro de Estudios Históricos "Profesor Carlos S. A. Segreti", 11 (11), pp. 17-39

Brenta, N. L. (2011b). Argentina. Crisis de pagos y sinergia entre programas del FMI y Club de París. 1956-2009. Temas de historia argentina y americana (Pontificia Universidad Católica Argentina "Santa María de Los Buenos Aires"), 17, pp. 53-74

Carranza, G. G. (2016). Constitucionalidad y oportunidad política en el nombramiento de los miembros de la Corte Suprema en Argentina. Especial alusión a la designación en comisión. Anuario de Derecho Constitucional Latinoamericano, 33

Carrera, N. I., Fernández, F. y Cotarelo, M. C. (2020). El movimiento obrero organizado ante la ofensiva de la oligarquía financiera argentina, 2016-2019. Tempo Social, 32(1), pp. 75-98

Casa Rosada (2018). Conferencia de prensa del ministro de Hacienda, Nicolás Dujovne. Emitido en directo el 9 may. 2018. YOUTUBE. Recuperado de: https://www.youtube.com/watch?v=78X1OfB61LA\&t=356s

Checkel, J. (1998). The Constructivist Turn in International Relations Theory. World Politics, 50 (1), pp. 324-348

Cornwall, A., \& Brock, K. (2005). What do buzzwords do for development policy? A critical look at 'participation', 'empowerment' and 'poverty reduction'. Third World Quarterly, 26(7), pp. 10431060

Cotarelo, M. C. (2008). Las protestas contra el FMI y la política estadounidense en Argentina reciente (2000-2006). En M. López Maya, N. I. Carrera y P. Calveiro, Luchas contrahegemónicas y cambios políticos recientes de América Latina. Buenos Aires: CLACSO

Cox, R. W. (2016). Gramsci, hegemonía y relaciones internacionales: Un ensayo sobre el método. Relaciones Internacionales, 31, PP. 137-152. Recuperado de: file://C:/Users/Notebook/Downloads/5301-Texto\%20del\%20art\%C3\%ADculo-10958-1-1020160630.pdf

Cuattromo, J. (2018). Las consecuencias del ajuste según el FMI. BORDES, 10, pp. 29-37

Dagatti, M. (2013). Contribuciones para una cartografía discursiva del primer kirchnerismo. En J. Balsa (comp.). Discurso, política y acumulación en el kirchnerismo (pp. 75-98). Buenos Aires: Centro Cultural de la Cooperación Floreal Gorini-Universidad Nacional de Quilmes. Recuperado de: https://www.researchgate.net/profile/Martin Retamozo/publication/284712591_Logicas politi cas_hegemonia_y_kirchnerismo/links/565647ee08ae1ef92979f6f4.pdf

Dalessandro, M. (2018). ¿Qué tiene que ver Ni Una Menos con el FMI? Economía en Portada. Economia Feminita. Recuperado de: https://economiafeminita.com/que-tiene-que-ver-ni-unamenos-con-el-fmi/

Di Marco, G. (2010). Los movimientos de mujeres en la Argentina y la emergencia del pueblo feminista. La aljaba, 14, pp. 51-67

Dinerstein, A. C. (2004). Más allá de la crisis. Acerca de la naturaleza del cambio político en Argentina. Revista Venezolana de Economía y Ciencias Sociales, 10(1), pp. 241-269

Doyle, D. (2012). Pressures to privatize? The IMF, globalization, and partisanship in Latin America. Political Research Quarterly, 65(3), pp. 572-585 
Druck, P., Magud N. E. \& Mariscal R. (2018). Collateral damage: Dollar strength and emerging markets' growth. The North American Journal of Economics and Finance, 43, pp. 97-117. Recuperado de: https://www.sciencedirect.com/science/article/abs/pii/S1062940817302188

Ellison, N., (2017). Politics, power and policy transfer. Journal of Asian Public Policy, 10 (1), pp. 824, DOI: $10.1080 / 17516234.2016 .1258519$

ENAC (2019). Cada día que trabaja Dante Sica cierran 60 pymes por día. Recuperado de: https://enac.org.ar/contenido/860/cada-dia-que-trabaja-dante-sica-cierran-60-pymes-enargentina

Fondo Monetario International (2011). Convenio Constitutivo del Fondo Monetario Internacional. Washington D.C. Recuperado de: https://www.imf.org/external/spanish/pubs/ft/aa/aa.pdf

Forster, T., Kentikelenis, A. E., Reinsberg, B., Stubbs, T. H. \& King, L. P. (2019). How structural adjustment programs affect inequality: a disaggregated analysis of IMF conditionality, 19802014. Social Science Research, 80, pp. 83-113

Giavedoni, J. G. (2018). La Revolución Libertadora y el surgimiento de la razón neoliberal. Realidad Económica, 47(317), pp. 9-40

Girón, A. (2010): Democracia, Washington Consensus y FMI en América Latina. En: O. de León Naveiro y G. Vidal Bonifaz. América Latina: Democracia, Economía y Desarrollo Social (pp. 31-42). Madrid: Trama editorial

Harvey, D. (2007). Breve Historia del Neoliberalismo, Madrid: Ed. Akal

IMF (June 2018). Argentina: Request for Stand-by Agreement. Press Release and Staff Report. Recuperado de: https://www.imf.org/en/Publications/CR/Issues/2018/07/13/ArgentinaRequest-for-Stand-By-Arrangement-Press-Release-and-Staff-Report-46078

IMF (September 2018). IMF and Argentina Authorities Reach Staff-Level Agreement on First Review Under the Stand-By Arrangement. Press Release No 18/362. Recuperado de: https://www.imf.org/en/News/Articles/2018/09/26/pr18362-argentina-imf-and-argentinaauthorities-reach-staff-level-agreement

IMF (October 2018). Argentina: First Review under the Stand-By Arrangement; Inflation Consultation; Financing Assurances Review; and Request for Rephasing, Augmentation, Waivers of Nonobservance and Applicability of Performance Criteria, and Modification of Performance Criteria. Press Release and Staff Report. IMF STAFF country Reports (18/297). Recuperado de: https://www.imf.org/en/Publications/CR/Issues/2018/10/26/Argentina-First-Review-under-theStand-By-Arrangement-Inflation-Consultation-Financing-46309

IMF (December 2018). Argentina: Second Review under the Stand-By Arrangement; Financing Assurances Review; and Request for Modification of Performance Criterion. Press Release; and Staff Report (18/374). Recuperado de: https://www.imf.org/en/Publications/CR/Issues/2018/12/19/Argentina-Second-Review-underthe-Stand-By-Arrangement-Financing-Assurances-Review-and-46485

IMF (April 2019). Argentina: Third Review under the Stand-By Arrangement, Request for Waivers of Applicability of Performance Criteria, Financing Assurances Review, and Request for Modification of Performance. IMF STAFF country Reports (19/99). Recuperado de: https://www.imf.org/en/Publications/CR/Issues/2019/04/05/Argentina-Third-Review-underthe-Stand-By-Arrangement-Request-for-Waivers-of-Applicability-46740

IMF (July 2019). Argentina: Fourth Review under the Stand-By Arrangement, Request for Waivers of Applicability and Modification of Performance Criteria, and Financing Assurances Review. Press Release (19/232). Recuperado de: https://www.imf.org/en/Publications/CR/Issues/2019/07/15/Argentina-Fourth-Review-underthe-Stand-By-Arrangement-Request-for-Waivers-of-Applicability-47116

INDEC (2020a). Índice de Precios al Consumidor (IPC). Índice de Precios. Ministerio de Economía, $\begin{array}{llllll}\text { vol. } & 4, & N^{\circ} & 1 . & \text { Recuperado }\end{array}$ https://www.indec.gob.ar/uploads/informesdeprensa/ipc 01_20578B3E8357.pdf 
INDEC (2020b). Incidencia de la pobreza y la indigencia en 31 aglomerados urbanos. Ministerio de $\begin{array}{llllll}\text { Economía, } & \text { vol. } & 4, & \mathrm{~N}^{\circ} & 4 . & \text { Recuperado de: }\end{array}$ https://www.indec.gob.ar/uploads/informesdeprensa/eph pobreza 02 195EFE752E31.pdf

INDEC (2020c). Evolución de la Distribución del Ingreso. Trabajo e Ingresos. Ministerio de Economía, vol. $4,4 \quad \mathrm{~N}^{\circ} \quad 4.4$ Recuperado https://www.indec.gob.ar/uploads/informesdeprensa/ingresos_1trim201BBF7C2BCC.pdf

INDEC (2020d). Mercado de Trabajo. Tasas e indicadores Socioeconómicos (EPH). Trabajo e Ingresos. Ministerio de Economía, vol. 4, $\mathrm{N}^{\circ} 3 . \quad$ Recuperado de: https://www.indec.gob.ar/uploads/informesdeprensa/mercado_trabajo_eph_1trim20AF03C167 7F.pdf

IOE (2004). Informe sobre la evaluación del papel del FMI en Argentina, 1991-2001. Recuperado de: https://www.imf.org/external/np/ieo/2004/arg/esl/063004.pdf

Jaquenod, A. M. (2018). Argentina y el MERCOSUR entre dos proyectos de integración regional: el ALCA y la UNASUR, 1989-2011 (Tesis Doctoral), Universidad Nacional de La Plata

Jiménez, J. P. y Lorenzo, F. (2010). Los cambios en el FMI y el impacto en su relación con los países de América Latina. En J. A. Alonso y A. Bárcena (coord.). Retos y oportunidades ante la crisis. Pensamiento Iberoamericano (pp. 255-283). Madrid: Agencia Española de Cooperación Internacional para el Desarrollo (AECID)-Fundación Carolina

Katz, C. I. (2017). El proyecto neoliberal en Argentina. Conicet. Recuperado de: https://ri.conicet.gov.ar/handle/11336/83362

Kedar, C. (2012). The international monetary fund and Latin America: the argentine puzzle in context. Temple University Press

Kentikelenis, A. E., Stubbs, T., \& Lawrence P. King, L. P. (2016). IMF conditionality and development policy space, 1985-2014. Review of International Political Economy, 23 (4), pp. 543-582

Kentikelenis, A., Karanikolos, M., Reeves, A., McKee, M., \& Stuckler, D. (2014). Greece's Health Crisis: From Austerity to Denialism. The Lancet, 383(9918), pp. 748-753

Keohane, R. O. (1984). After Hegemony: Cooperation and Discord in the World Political Economy. Princeton, NJ: Princeton University Press

La Via Campesina (2018). Get out IMF: Workers Unions and Peasants mobilise in large numbers in Argentina. Recuperado de: https://viacampesina.org/en/get-out-imf-workers-unions-andpeasants-mobilise-in-large-numbers-in-argentina/

Lang, V. F. (2016). The economics of the democratic deficit: The effect of IMF programs on inequality. University of Heidelberg Department of Economics Working Paper, 617

Lesage, D., Debaere, P., Dierckx, S., \& Vermeiren, M. (2013). IMF reform after the crisis. International Politics, 50(4), pp. 553-578

Manzo, A. G., y Salva, C. G. (2012). La crisis del neoliberalismo en Argentina. Una mirada retrospectiva sobre las causas del default 2001: buscando razones para entender el quiebre de nuestro país y con el FMI. Passagens, 4(2), pp. 299-327

Martínez, F. (2013). Aproximación a algunos tópicos del "discurso kirchnerista". En J. Balsa (comp.). Discurso, política y acumulación en el kirchnerismo (pp. 53-67). Buenos Aires: Centro Cultural de la Cooperación Floreal Gorini-Universidad Nacional de Quilmes. Recuperado de: https://www.researchgate.net/profile/Martin_Retamozo/publication/284712591_Logicas_politi cas_hegemonia_y_kirchnerismo/links/565647ee08ae1ef92979f6f4.pdf

Martone, F. (2004). Sin el fondo ¿quién estará fuera del mundo?: Teoría y práctica de la intervención del FMI en América Latina. Íconos: revista de ciencias sociales (FLACSO, sede Ecuador), 19, pp. 124-129

Ministerio del Interior (2019). Elecciones electorales. Escrutinio definitivo. 2001. Recuperado de: http://www.elecciones.gov.ar/estadistica/archivos/2001/BsAsTotDistr2001.pdf 
Ministro de Hacienda (junio, 2018). Acuerdo Argentina-FMI. Argentina Gobierno. Recuperado de: https://www.argentina.gob.ar/sites/default/files/acuerdo_argentina-fmi-final1.pdf

Morgenfeld, L. (2017). Macri y el fracaso de la subordinación a Estados Unidos: de Obama a Trump. Realidad Económica. Recuperado de: http://www.iade.org.ar/system/files/macri y el fracaso de la subordinacion a eeuu de oba ma_a_trump_morgenfeld.pdf

Mueller, J. L. (2011). The IMF, neoliberalism and hegemony. Global Society, 25(3), pp. 377-402

Musacchio, A. (2020). Neoliberalismo, inserción internacional y financiarización: una comparación entre Argentina y Portugal. Problemas del Desarrollo. Revista Latinoamericana de Economía, 51(201)

Naddeo, M. E. (2015). Los derechos de las Mujeres y el impacto de los procesos de ajuste estructural. En S. Pérez Gallart. Las Conquistas de las Mujeres en 30 años de Democracia (pp. 83-94), Asamblea Permanente por los Derechos Humanos

Natalucci, A. L. y Rey, J. (2018). ¿Una nueva oleada feminista? Agendas de género, repertorios de acción y colectivos de mujeres (Argentina, 2015-2018). Revista de Estudios Políticos y Estratégicos, 6 (2). Recuperado de: https://revistaepe.utem.cl/articulos/una-nueva-oleadafeminista-agendas-de-genero-repertorios-de-accion-y-colectivos-de-mujeres-argentina-2015$\underline{2018 /}$

Natanson, J. (2019). Argentina: elecciones en tiempos de grieta. Nueva sociedad, 281, pp. 4-11

Nelson, S. C. (2017). The currency of confidence: How economic beliefs shape the IMF's relationship with its borrowers. Cornell University Press

Nemiña, P. (2011). Ajuste, crisis y default: el FMI y la Argentina durante la gestión de De la Rúa (19992001). Anuario del Centro de Estudios Históricos "Prof. Carlos SA Segreti", 11(11), pp. 41-61

Nemiña, P. y Echandi, J. (2020). De la red al piso de protección social: la trayectoria de la política social en los organismos multilaterales. Conjuntura Austral, 11(55), pp. 51-62

Nemiña, P. y Larralde, J. (2020). Prestamista, garante y deudor: el FMI en América Latina y el Caribe en la década posterior a la crisis financiera. Sociedade e Cultura, 23

Pautassi, L., Arcidiácono, P., y Straschnoy, M. (2014). Condicionando el cuidado: la Asignación Universal por Hijo para la protección social en Argentina. Iconos (FLACSO, sede Ecuador), 50, pp. 61-75

Pénet, P. (2018). The IMF failure that wasn't: Risk ignorance during the European debt crisis. British Journal of Sociology, 69 (4), pp. 1031-1055

Petropoulou, C. (2015). Acumulación por desposesión y movimientos sociales urbanos regionales en la crisis de Grecia. Revista Ábaco• $2^{a}$ época, 2 (3), pp. 82-96

Retamozo, M. (2011). El kirchnerismo y los movimientos sociales. Lógicas políticas y hegemonía en Argentina. IX Jornadas de Sociología, Facultad de Ciencias Sociales, Universidad de Buenos Aires, Buenos Aires. Recuperado de: http://www.aacademica.org/000-034/575. Consulta: 20 de septiembre de 2016

Retamozo, M., y Di Bastiano, R. (2017). Los movimientos sociales en Argentina. Ciclos de movilización durante los gobiernos de Néstor Kirchner y Cristina Fernández de Kirchner 20032015. Cuadernos del CENDES (Universidad Central de Venezuela. Centro de Estudios del Desarrollo), 34 (95), pp. 117-153

Revelez, L. B. (2008). El proceso regional del MERCOSUR en el siglo XXI: del regionalismo abierto a la prioridad estratégica sudamericana. Revista Aportes para la Integración Latinoamericana, 19, pp. 1-22

Riggirozzi, M. P. (2005). The World Bank as a norm-broker: knowledge, funds and power in governance reforms in Argentina (Doctoral dissertation). University of Warwick 
Sainz, C. G. (2017). El impacto de la crisis económica en la pobreza de tiempo y la desigualdad de género. Arbor, 193(784), p. 382

Sánchez Pastor, P., y Serra Stecher, X. (2015). Las nuevas líneas protectoras del FMI. Boletín económico/Banco de España, junio 2015, pp. 69-84

Slimovich, A. (2017). Los enunciadores políticos de la protesta por el aumento de tarifas en Argentina. Un análisis hipermediático de un movimiento social contemporáneo. De Signos y Sentidos (Ediciones UNL), 18, pp. 9-34

Tabbush, C., Díaz, M. C., Trebisacce, C. y Keller, V. (2016). Matrimonio igualitario, identidad de género y disputas por el derecho al aborto en Argentina. La política sexual durante el kirchnerismo (2003-2015). Sexualidad, Salud y Sociedad (Rio de Janeiro), 22, pp. 22-55

Taylor, I. (2004). Hegemony, neoliberal 'good governance' and the International Monetary Fund: a Gramscian perspective. En M. Boas \& D. McNeill (ed.). Global Institutions and Development (pp. 142-154). London: Routledge

Torre, J.C. (2005). Los huérfanos de la política de partidos. Sobre los alcances y naturaleza de la crisis de representación partidaria. En T. Di Tella y C. Lucchini (coord.). Sociedad y Estado en América Latina. Conceptos teóricos y transformaciones históricas. Buenos Aires: Biblos/Fundación Simón Rodríguez

Varesi, G. Á. (2016). La contra-ofensiva neoliberal: estrategia político-económica de reestructuración societaria en el primer semestre de Macri. En IX Jornadas de Sociología de la Universidad Nacional de La Plata (Ensenada, 2016)

Weisbrot M. y Merling L. (2018). El acuerdo de Argentina con el FMI ¿Funcionará la "austeridad expansiva"? CEPR Center for Economic and Policy Research, pp. 1-18 